\title{
CRISPR-CAS9, BIOSSEGURANÇA E BIOÉTICA: UMA ANÁLISE JUSFILOSÓFICA-AMBIENTAL DA ENGENHARIA GENÉTICA
}

Émilien Vilas Boas Reis

\author{
Pós-doutor em Filosofia pela Universidade do Porto (2014), doutor em Filosofia pela \\ Pontifícia Universidade Católica do Rio Grande do Sul (2010), mestre em Filosofia pela \\ Pontifícia Universidade Católica do Rio Grande do Sul (2006) e graduação em Filosofia pela \\ Universidade Federal de Minas Gerais (2004). É Professor adjunto da Escola Superior Dom \\ Helder Câmara (Belo Horizonte) em nível de graduação \\ e pós-graduação (mestrado/doutorado). \\ E-mail:mboasr@yahoo.com.br
}

Bruno Torquato de Oliveira

Doutor e mestre em Direito pela PUC Minas, professor do Mestrado em Direito Ambiental e Desenvolvimento Sustentável da Escola Superior Dom Helder Câmara (Belo Horizonte). É coordenador do curso de especialização em Direito Urbanístico e Ambiental da PUC Minas Virtual, professor nos cursos de graduação e especialização em Direito da PUC Minas e da Escola Superior Dom Helder Câmara e pesquisador do Centro de Estudos em Biodireito - CEBID (cebid.com.br). E-mail: brunotorquato@hotmail.com

\section{RESUMO}

A nova técnica de engenharia genética CRISPR-Cas9 projeta benefícios e riscos de se manipular e alterar geneticamente organismos vivos, de forma a trazer características favoráveis a eles mesmos e aos seres humanos. Com abordagem interdisciplinar, envolvendo a Filosofia, o Direito, a Biossegurança e a Bioética, o artigo objetiva verificar quais as consequências que o uso da referida técnica pode trazer à natureza genética dos organismos, sobretudo dos pontos de vista ético e jurídico. Como referência jurídica e de Biossegurança, optou-se pela Lei brasileira n. 11.105/2005 e, como referência filosófica e bioética, abordou-se a controvérsia entre os pensadores alemães Jürgen Habermas e Peter Sloterdijk, que analisaram o tema da engenharia genética e do risco da eugenia. Trata-se de pesquisa teórico-bibliográfica, que emprega o raciocínio dedutivo sobre os impactos jurídicos-filosóficos do uso da técnica do CRISPR-Cas9. A prática da engenharia genética, apesar dos riscos, pode ser um procedimento inevitável diante do atual estágio de desenvolvimento humano e enfrentála com a compreensão das responsabilidades jurídica e bioética torna-se essencial.

Palavras-chave: CRISPR-Cas9; manipulação genética; engenharia genética; biossegurança; bioética. 
CRISPR-CAS9, BIOSAFETY AND BIOETHICS: A

JUSPHILOSOPHICAL AND ENVIRONMENTAL ANALYSIS OF

GENETIC ENGINEERING

\section{ABSTRACT}

The new genetic engineering technique CRISPR-Cas 9 projects benefits and risks of genetically manipulating and altering living organisms in order to bring about characteristics that are favorable to themselves and to humans. With an interdisciplinary method, involving Philosophy, Law, Biosafety and Bioethics, this paper aims to verify the consequences that the use of this technique can bring to the genetic nature of organisms, especially from the ethical and legal points of view. As a legal and biosafety reference, we opted for Brazilian Law n. 11.105/2005 and for philosophical and bioethical reference, we approach the controversy between the German thinkers Jürgen Habermas and Peter Sloterdijk, who analyzed the subject of genetic engineering and the risk of eugenics. It is a theoretical-bibliographic research, which uses deductive reasoning on the legal-philosophical impacts of the CRISPR-Cas 9 technique. The practice of genetic engineering, despite the risks, may be an inevitable procedure in the present stage of human development and confronting it with an understanding of legal and bioethical responsibilities becomes essential.

Keywords: CRISPR-Cas9; genetic manipulation; genetic engineering; biosafety; bioethics. 


\section{INTRODUÇÃO}

A manipulação genética sempre esteve envolta em polêmicas bioéticas e jurídicas. No entanto, nos últimos anos uma nova técnica de engenharia genética tem prometido revolucionar os caros processos de alteração genética.

A técnica do CRISPR-Cas9 permite substituir fragmentos da cadeia de DNA por outros, corrigindo "falhas" genéticas ou inserindo caracteres benéficos em um determinado organismo.

A possibilidade de ter o controle sobre o genoma e as características genéticas dos organismos suscita a reflexão sobre os riscos de uma natureza projetada para os interesses humanos e, ainda, os riscos de práticas eugênicas quando essas alterações se voltam para o genoma humano.

A presente pesquisa apresenta um estudo interdisciplinar, envolvendo a Filosofia, o Direito, a Biossegurança e a Bioética no intuito de verificar como a técnica do CRISPR-Cas9 pode repercutir no que conhecemos como natureza genética dos organismos vivos, enfrentando os problemas éticos e jurídicos trazidos. A referência jurídica e de Biossegurança será a Lei brasileira n. 11.105/2005, que aborda as questões da manipulação e engenharia genéticas, tanto em células humanas quanto de outros organismos vivos.

Para refletir sob a perspectiva filosófica e bioética, o artigo utiliza a controvérsia entre os pensadores alemães Jürgen Habermas e Peter Sloterdijk, que analisaram o tema da engenharia genética e do risco da eugenia.

Trata-se, pois, de pesquisa teórico-bibliográfica, que emprega o raciocínio dedutivo dos impactos jurídicos-filosóficos do uso da técnica do CRISPR-Cas9.

Para tanto, inicia-se por uma exposição do que consiste a técnica do CRISPR-Cas9, em seus aspectos biológicos e biotecnológicos.

Em seguida, aborda-se o tratamento legal da Biossegurança no Brasil. Após contextualizar a Biossegurança e seu desenvolvimento, analisa-se alguns dispositivos da Lei n. 11.105/2005, pretendendo dar um panorama de seu tratamento jurídico, dando ênfase às normas referentes à manipulação e engenharia genéticas.

Por fim, confronta-se a técnica do CRISPR-Cas9 com a terapia gênica por meio de adenovírus ou retrovírus e faz-se uma exposição dos riscos das técnicas frente à Bioética. 


\section{CRISPR-CAS9: UMA ANÁLISE}

CRISPR é um acrônimo da expressão em inglês Clustered Regularly Interspaced Short Palindromic Repeats (Repetições Palindrômicas Curtas Agrupadas e Regularmente Interespaçadas). A primeira vez que uma sequência de CRISPR foi identificada ocorreu em um estudo na bactéria Escherichia coli em 1987, apesar de ainda não ser compreendida com tal nome (ISHINO et al., 1987). Os pesquisadores japoneses notaram em certas sequências de DNA pedaços de genes que não pertenciam naturalmente ao genoma da Escherichia coli. No início dos anos 2000, o pesquisador espanhol Francisco Mojica (2000) identificou o CRISPR em outras diferentes espécies, como arqueas e outros microrganismos unicelulares.

O papel do CRISPR será, então, associado a uma capacidade de defesa natural de bactérias e arqueias contra vírus (MAKAROVA et al., 2006), o que justificaria que os genes que não fazem parte do genoma dos organismos estudados seriam adaptações aos ataques ocorridos desses vírus:

[...] bacteria and archaea would have sophisticated immune systems. After all, viruses are the most abundant biological agents on the planet, causing roughly infections every second. The selective pressures imposed by viral predation have resulted in the evolution of numerous phage defense systems, but it was only recently that sophisticated adaptive defense systems were identified in both bacteria and archaea (ERP et al., 2015, p. 85).

Tal hipótese será comprovada em 2007 por cientistas de origem americana, francesa e canadense, que trabalhavam para a Danisco, uma companhia alimentícia dinamarquesa. Os pesquisadores partiram da noção de que muitas bactérias são usadas para a fermentação e processos biotecnológicos de alimentos, mas que tais bactérias são atacadas por fagos, que, muitas vezes, não são combatidas pelos processos habituais (BARRANGOU et al., 2007).

Os pesquisadores estudaram uma bactéria de fermentação do leite para a produção de alimentos como iogurte e queijo chamada Streptococcus thermophilus. Eles fizeram um experimento com bactéria e dois bacteriófagos que já haviam sido isolados pela indústria de iogurte. 
Mais nove fagos foram gerados do experimento entre a bactéria e os dois fagos tomados previamente. Posteriormente, a bactéria se mostrou imune aos novos fagos e os autores se questionaram sobre o motivo. Ao compararem os DNAs da bactéria e dos novos fagos, os autores afirmaram que a resistência do Streptococcus thermophilus se deveu ao fato do CRISPR no DNA da bactéria ter se adaptado ao DNA dos fagos: "These results reveal that, on becoming resistant to bacteriophages, the CRISPR locus was modified by the integration of novel spacers, apparently derived from phage DNA.” (BARRANGOU et al., 2007, p. 1710).

Em outras palavras:

[...] CRISPR functioned like a molecular vaccination card: by storing memories of past phage infections in the form of spacer DNA sequences buried within the repeatspacer arrays, bacteria could use this information to recognize and destroy those same invading phages during future infections (DOUDNA; STERNBERG, 2017, p. 56).

As bactérias, portanto, teriam uma capacidade de recordar os vírus que já lhe infectaram, a partir do DNA desses vírus, que seriam incorporados aos CRISPRs das bactérias. Quando as bactérias eram atacadas novamente pelos vírus, elas estavam resistentes.

Os estudos nas bactérias seriam apenas o início da análise sobre o CRISPR. A partir de então, uma série de artigos se debruçou sobre ele, no entanto, sem entender como ocorria todo o procedimento envolvido. Já se sabia, contudo, que o processo para a resistência das bactérias dependia da atuação de moléculas-guia de RNA. Um estudo verificou que o RNA seria o responsável por coordenar o reconhecimento e a destruição das infecções viróticas, e que isso envolveria o sistema de defesa CRISPR. As moléculas de RNA eram produzidas pelas células, por meio do CRISPR, para combater as sequências do DNA do vírus invasor (BROUNS et al., 2008). Em suma,

CRISPR loci are transcribed, and the long primary transcript is processed into a library of short CRISPR-derived RNAs (crRNAs) that each contain a sequence complementary to a previously encountered invading nucleic acid. Each crRNAs is packaged into a large surveillance complex that patrols the intracellular environment and mediates the detection and destruction of foreign nucleic acid targets (WIEDENHEFT; STERNBERG; DOUDNA, 2012, p. 331). 
Além do CRISPR e da participação do RNA em seu desempenho, a atenção dos pesquisadores também deveria se debruçar sobre o Cas genes, que está presente na região dos genomas da bactéria e que contém tipos especiais de proteínas denominadas enzimas, que funcionam como catalizadores das reações moleculares nas células. Assim, ao compreenderem o papel da proteína Cas nesse processo, poderiam entender como o CRISPR funciona realmente (DOUDNA; STERNBERG, 2017, p. $62)$.

Blake Wiedenheft, um pesquisador que trabalhava com Jennifer Doudna, uma das que viriam a descobrir a capacidade do CRISPR em "cortar" qualquer tipo de gene, conseguiu separar inúmeras proteínas Cas em um experimento (DOUDNA; STERNBERG, 2017, p. 63-64). De posse dessas proteínas Cas, Wiedenheft et al. (2009) acharam uma proteína enzima Cas1, que tinha a capacidade de cortar o DNA, o que sugeriria que a proteína tinha um papel ao longo do processo de constituição do sistema de defesa e adequação dos DNAs dos organismos aos ataques de vírus. Outras proteínas Cas iam sendo manipuladas e descobertas. Enfim, podese elucidar que os sistemas de defesa bacteriano tinham vários tipos de proteínas Cas, que possuíam a função de "procurar" e "cortar" ("clivar") os DNAs viróticos, impedindo sua ação. Descobriu-se assim, a atuação do meio de defesa que envolve o CRISPR. Inicialmente, a molécula de CRISPR RNA (crRNA), que possui dez ou onze diferentes proteínas Cas, atua na conservação aos ataques dos DNAs dos vírus, localizandoos. Em seguida, as proteínas enzimas Cas atuam, "cortando" o DNA alvo (DOUDNA; STERNBERG, 2017, p. 63; 66). Tal processo inativa os genes dos vírus e impede que eles ajam.

Dentre as proteínas Cas estudadas, a que causou maior impacto foi a $\operatorname{Cas} 9$ (que ficará conhecida como parte do sistema CRISPR tipo II $^{1}$ ). Jennifer Doudna e Emmanuelle Charpentier comandaram uma equipe que descobriram o singular papel da Cas9:

\footnotetext{
1 Sobre uma explicação técnica a respeito dos tipos de sistemas CRISPR/Cas: "There are three types of CRISPR/Cas systems (21-23). The type I and III systems share some overarching features: specialized Cas endonucleases process the pre-crRNAs, and oncemature, each crRNA assembles into a large multiCas protein complex capable of recognizing and cleaving nucleic acids complementary to the crRNA. In contrast, type II systems process pre-crRNAs by a different mechanism in which a trans-activating crRNA (tracrRNA) complementary to the repeat sequences in pre-crRNA triggers processing by the double-stranded (ds) RNA-specific ribonuclease RNase III in the presence of the Cas9 (formerly Csn1) protein (fig. S1) $(4,24)$. Cas9 is thought to be the sole protein responsible for crRNA-guided silencing of foreign DNA (25-27)." (JINEK et al., 2012, p. 16).
} 
They had independently been teasing out the roles of various CRISPR-associated proteins to learn how bacteria deploy the DNA spacers in their immune defenses. But the duo soon joined forces to focus on a CRISPR system that relies on a protein called Cas9, as it was simpler than other CRISPR systems.

When CRISPR goes into action in response to an invading phage, bactéria transcribe the spacers and the palindromic DNA into a long RNA molecule that the cell then cuts into short spacer-derived RNAs called crRNAs. An additional stretch of RNA, called tracrRNA, works with Cas9 to produce the crRNA [...] (PENNISI, 2013, p. 834).

As descobertas até aqui ocorriam no nível natural. A grande questão que surgiu, em seguida, é se os pesquisadores poderiam, eles mesmos, se valerem da $\operatorname{Cas} 9$ para manipularem e cortarem manualmente outras sequências de DNAs: "What we wanted to do next was confirm that we could engineer Cas9 and the RNA molecules to target and cut any DNA sequence of our choice.” (DOUDNA; STERNBERG, 2017, p. 81).
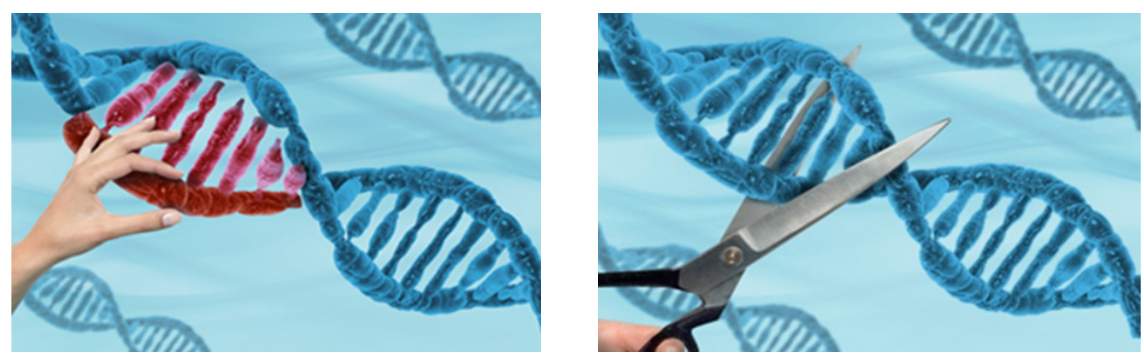

Ilustrações sobre o método CRISPR-CAS9: Esquerda - Corte do DNA; Direita - Manipulação do DNA. Créditos: Renato Serra

Jennifer Doudna, Emmanuelle Charpentier e equipe resolveram fazer um experimento para comprovar as hipóteses levantadas a respeito do CRISPR-Cas9. Decidiram usar genes de uma água-viva para o experimento. O pesquisador Martin Jinek fez o processo manualmente da atuação do CRISPR e do $\operatorname{Cas} 9$. Escolheu cinco diferentes sequências de genes e preparou "quimericamente" cinco moléculas de RNA para combiná-los. Então, incubou o RNA com o Cas 9 e o DNA da água-viva e esperou o resultado. Verificou, então, que o DNA da água-viva estava cortado. As moléculas de RNA haviam atuado no exato lugar onde o pesquisador havia selecionado para o "corte", ocorrido através do Cas9. Estava validada e construída uma nova tecnologia capaz de editar qualquer 
genoma em qualquer organismo! (DOUDNA; STERNBERG, 2017, p. 8283). Sem descrever propriamente a pesquisa relatada, a novidade a respeito da manipulação CRISPR/Cas9 foi referida num artigo do mesmo corpo de cientistas que saiu em agosto de 2012:

Our study further demonstrates that the Cas 9 endonuclease family can be programmed with single RNA molecules to cleave specific DNA sites, thereby raising the exciting possibility of developing a simple and versatile RNA-directed system to generate dsDNA breaks for genome targeting and editing (JINEK et al., 2012, p. 816).

Tal estudo desencadearia uma série de pesquisas envolvendo o CRISPR e suas potencialidades. Vários artigos iriam trabalhar a edição genética de diferentes tipos de células. Além da indústria de laticínios, que já se valia das incipientes aplicações do CRISPR, diversas outras áreas passariam a se beneficiar da técnica, tais como o agronegócio, outras áreas de alimentação, a biotecnologia e a área médica. ${ }^{2} \mathrm{O}$ motivo para o progresso de pesquisas com CRISPR envolveu a capacidade de manipulação genética, mas também a facilidade de manipulação e o baixo custo: "But the real reason that CRISPR exploded onto the biotech scene with such force and vitality was its low cost ande ase of use. CRISPR finally made gene editing available to all scientists.” (DOUDNA; STERNBERG, 2017, p. 111). Outro fator que tem contribuído para a revolução do CRISPR é o avanço da tecnologia computacional:

Computers have also made gene editing easier than ever before. Using advanced algorithms that incorporate all the relevant design principles, including empirical data from the scientific literature on what kinds of targeting sequences work better than others, various software packages offer researchers an automated, one-step method to build the best version of CRISPR to edit a given gene (DOUDNA; STERNBERG, 2017, p. 112).

Os avanços prosseguiram. Em maio de 2013, Wang et al. (2013) fizeram um experimento com o CRISPR que também abriria inúmeras possibilidades para o que talvez seja um dos grandes dilemas que o método teria que enfrentar: a manipulação de células germinativas e embriões. Além da primeira edição celular embrionária, a pesquisa foi capaz de fazer várias manipulações simultaneamente. $\mathrm{E}$ apesar da técnica empregada

2 Para informações a respeito da entrada da técnica CRISPR no mercado Cf. ERP et al. (2015). 
ter manuseado um embrião, ela abria a possibilidade para que o CRISPR pudesse ser usado em óvulos e espermatozoides, o que permitiria transmitir mudanças genéticas para as gerações posteriores: “[...] it seemed that CRISPR could be injected into any species' germ cells (eggs and sperm) or embryos, and the resulting genetic changes would be faithfully copied into all the cells and forever transmitted to future offspring" (DOUDNA; STERNBERG, 2017, p. 98).

Mesmo antes da técnica CRISPR ser utilizada oficialmente na edição de embriões humanos nos Estados Unidos, vários cientistas assinaram um manifesto denominado Don't edit the human germ line, em que clamaram aos seus pares para que não desenvolvessem tal pesquisa antes que uma séria discussão ética fosse levantada. O texto chama a atenção ao fato de que até aquele momento, março de 2015, várias pesquisas que usavam a técnica CRISPR já vinham sendo feitas com outros animais, o que seria um passo para a pesquisa em com células germinativas (óvulo e espermatozoide) humanas: "Studies using gene-editing in animals such as rats, cattle, sheep and pigs, indicate that it is possible to delete or disable genes in an embryo - a simpler process than actually correcting DNA sequences - in onlysome of the cells (LAMPHIER et al., 2015, p. 411). Manipulações com células germinativas humanas já vinham sendo feitas com outras técnicas, mas, com o CRISPR, as alterações poderiam ser transmitidas para as gerações posteriores. Devido a possíveis riscos, muitos países que têm capacidade técnica para fazerem manipulações genéticas em células germinativas se valem do aspecto jurídico para proibirem as alterações:

Many countries do not have explicit legislation in place permitting or forbidding genetic engineering in humans - considering such research experimental and not therapeutic (see go.nature.com/uvthmu). However, in nations with policies regarding inheritable genetic modification, it has been prohibited by law or by measures having the force of law. This consensus is most visible in western Europe, where 15 of 22 nations prohibit the modification of the germ line. Although the United States has not officially prohibited germline modification, the US National Institutes of Health's Recombinant DNA Advisory Committee explicitly states that it "will not at present entertain proposals for germ line alterations" (see go.nature.com/mgscb2) (LAMPHIER et al., 2015, p. 411). 
O fato de existirem legislações mais duras em países do ocidente europeu, abre uma maior possibilidade da manipulação genética em nível germinativo com a técnica CRISPR ocorrer nos demais países, como será visto posteriormente.

O manifesto de Lamphier et al. (2015) é explícito em afirmar que o grande receio é a prática eugênica e os possíveis danos à própria linhagem humana, por isso, um debate público com especialistas, acadêmicos e a opinião pública é fundamental para que se possa discutir se e em quais circunstâncias a técnica de manipulação em nível germinativo em humanos deva ocorrer, o que não implicaria, contudo, em excluir toda pesquisa que envolva manipulação genética.

Em 28 de outubro de 2016 a técnica CRISPR-Cas9 foi testada pela primeira vez em um ser humano. Uma equipe chinesa, liderada pelo oncologista Lu You, da Universidade de Sichuan, em Chengdu, modificou células com a técnica CRISPR para combater um câncer de pulmão em um paciente. $O$ processo consistiu na retirada de células imunes do sangue do paciente, que foram manipuladas com o CRISPR-Cas9. Dessa forma, foi desativado (cortado) um determinado gene, que tem como função codificar a proteína PD-1. Tal proteína, eventualmente, prejudica a resposta imune das células, provocando a proliferação de cânceres. As células editadas foram cultivadas e seu número aumentado. Posteriormente, elas foram novamente injetadas no paciente. A esperança da equipe é que as células editadas sem o PD-1 ataquem o câncer (CIRANOSKI, 2016).

O tratamento descrito acima foi contra o câncer, entretanto, deve-se enfatizar que o método CRISPR-Cas9 tem sido aplicado ao estudo de diversas doenças, pelo fato de poder reverter mutações ou trocar um gene danificado por outros saudáveis, ainda que existam doenças que, por enquanto, não sejam potencialmente tratadas pelo CRISPR-Cas9:

Beyond cancer, HIV, and the genetic disorders discussed thus far, a quick survey of the published scientific literature reveals a growing list of diseases for which potential genetic cures have been developed with CRISPR: achondroplasia (dwarfism), chronic granulomatous disease, Alzheimer's disease, congenital hearing loss, amyotrophic lateral sclerosis (ALS), high cholesterol, diabetes, Tay-Sachs, skin disorders, fragile $\mathrm{X}$ syndrome, and even infertility. [...] There are all sorts of disorders — from autism to heart disease - that don't show significant genetic causation or are caused by a complex combination of genetic variants and environmental factors. In these cases, gene editing may be of more limited use (DOUDNA; STERNBERG, 2017, p. 181182). 
Os ganhos com o CRISPR-Cas9 e o impacto real de sua técnica contribuíram para que as National Academies of Sciences, Engineering, and Medicine (2017) dos Estados Unidos fizessem um relatório denominado Human Genome Editing: science, ethics, and governance ${ }^{3}$ em que tomam uma posição favorável à manipulação genética em embriões e células germinativas, desde que seguindo algumas diretrizes. As conclusões do comitê podem ser sintetizadas nos seguintes princípios e observações finais:

Genome editing holds great promise for preventing, ameliorating, or eliminating many human diseases and conditions. Along with this promise comes the need for ethically responsible research and clinical use.

RECOMMENDATION 2-1. The following principles should undergird the oversight systems, the research on, and the clinical uses of human genome editing:

1. Promoting well-being

2. Transparency

3. Due care

4. Responsible science

5. Respect for persons

6. Fairness

7. Transnational cooperation (NATIONAL..., 2017, p. 182)

Esses princípios, por sua vez, vão resultar em responsabilidades para a edição do genoma humano. A seguir, explica-se cada um dos princípios elencados e suas respectivas responsabilidades atreladas.

1. Promoção do bem-estar: deve-se sempre buscar o benefício (princípio da beneficência) e a prevenção dos danos (princípio da nãomaleficência) dos envolvidos nas pesquisas $\rightarrow$ As responsabilidades procedidas são: a) usar a edição de genoma humano para tratamentos ou prevenção de doenças e não aplica-la em casos de grande incerteza; b) buscar os benefícios tendo também em vista os riscos envolvidos.

2. Transparência: deve-se dar informações aos interessados de forma clara e compreensível $\rightarrow$ As responsabilidades procedidas são: a) comprometimento com a exposição do maior número de informações e de maneira célere; b) ceder informações para a construção de políticas públicas.

3 O relatório contém 310 páginas e traz muitas questões que poderiam ser analisadas de maneira pormenorizada. Optou-se, propositalmente, por enfatizar alguns determinados aspectos que se mostraram relevantes para este paper. 
3. Devido cuidado: deve-se ter um cuidado com os envolvidos, agindo somente baseado em firmes evidências $\rightarrow$ A responsabilidade procedida é: agir com precaução e frequente reavaliação das ações, levando também em conta as opiniões culturais.

4. Ciência responsável: deve-se agir baseado somente em altos padrões de pesquisa, seguindo as diretrizes de normas internacionais e profissionais. $\rightarrow$ As responsabilidades procedidas são: a) fazer pesquisa de alto padrão; b) revisar e avaliar as pesquisas seguindo os protocolos; c) ser transparente; d) corrigir informações equivocadas.

5. Respeito pelas pessoas (persons): deve-se reconhecer a dignidade de todos os indivíduos, respeitando suas decisões particulares, além de tomar todos os indivíduos com o mesmo valor moral, independentemente de suas propriedades genéticas. $\rightarrow$ As responsabilidades procedidas são: a) ter um mesmo comprometimento com todos; b) ter respeito às decisões; c) prevenir práticas eugénicas, como as já praticadas; d) desestigmatizar as deficiências.

6. Equidade: deve-se tratar os casos semelhantes da mesma maneira e praticar a justiça distributiva em relação aos riscos e benefícios. As responsabilidades procedidas são: a) fazer a distribuição de tarefas e benefícios das pesquisas; b) possibilitar o acesso universal e equitativo dos benefícios alcançados pelas investigações.

7. Cooperação transnacional: deve haver uma colaboração internacional de pesquisa, levando-se em consideração os diferentes contextos culturais. As responsabilidades procedidas são: a) ter respeito pelas diferentes políticas nacionais; b) buscar normas comuns; c) partilhar dados alcançados.

Provavelmente, o relatório incentivou que pesquisas com embriões fossem realizadas nos Estados Unidos com a técnica CRISPRCas9. Alguns meses depois, isso se confirmou através de uma investigação que envolveu pesquisadores de diferentes nacionalidades e liderados por Shoukhrat Mitalipov, pesquisador da Oregon Health and Science University, em Portland. Foi o primeiro experimento com embriões nos Estados Unidos, financiado por setores privados, já que o governo americano não financia trabalhos que envolvam embriões humanos (LEDFORD, 2017). Os autores usaram a técnica do CRISPR-Cas9 para retificarem uma mutação geradora de doenças em embriões. A pesquisa consistiu em trabalhar a mutação de um gene denominado MYBPC3, geradora da cardiomiopatia hipertrófica, uma doença que resulta em 
insuficiência cardíaca e é a causa mais comum de morte súbita em atletas jovens e saudáveis. A taxa de embriões manipulados que não tinham o gene mutante foi alta (MA, 2017) ${ }^{4}$. O pioneirismo da pesquisa em solo americano colocou o país numa disputa silenciosa com a China pelas pesquisas embrionárias com a técnica CRISPR-Cas9.

Em meados de 2018, o método CRISPR-Cas9 recebeu dois pesados reveses: por um lado, dois textos (HAAPANIEMI et al., 2018; IHRY et al., 2018) mostraram evidências de que a edição genética com o CRISPR-Cas9 favorece o aparecimento de tumores, por outro, um estudo (KOSICKI; TOMBERG; BRADLEY, 2018) destacou que o CRISPR-Cas9 pode causar maior destruição genética do que os especialistas pensavam. Apesar de não serem estudos que colocam em xeque definitivamente a técnica, eles alertam para possíveis danos colaterais que devem ser mais aprofundados.

No primeiro caso, apesar de pesquisarem tipos diferentes de células, células epiteliais do pigmento da retina humana (HAAPANIEMI et al., 2018) e células-tronco pluripotentes humanas (human pluripotent stem cells - hPSCs) (IHRY et al., 2018), os pesquisadores notaram que o corte no DNA com o CRISPR-Cas9 ativa um gene denominado p53, que tem a função de lidar com o dano causado pelo corte: "Here, we report that genome editing by CRISPR-Cas9 induces a p53-mediated DNA damage response [...]" (HAAPANIEMI et al., 2018, p. 927). É como se o organismo tentasse se readequar após o corte, fazendo com que, muitas vezes, o CRISPR não tenha a eficácia esperada: "The toxic response to DSBs ${ }^{5}$ was P53/ TP53-dependent, such that the efficiency of precise genome engineering in hPSCs with a wild-type p53 gene was severely reduced (IHRY et al., 2018, p. 939). Ou seja, o efeito do CRISPR dependeria da não atuação do gene p53. "These results suggest that p53 inhibition may improve the efficiency of genome editing of untransformed cells and that p53 function should be monitored when developing cell-based therapies utilizing CRISPR-Cas9" (HAAPANIEMI et al., 2018, p. 927). Mas o problema está justamente nisso, pois quando p53 não atua (naturalmente ou induzido), o risco de câncer aumenta exponencialmente, o que sugeriria, a princípio, um risco no uso da técnica: "P53 inhibition could alleviate toxicity but has the potential to increase off-target mutations and poses a risk for cancer." (IHRY et al., 2018,

4 Os resultados do experimento, que seriam devidos à técnica CRISPR-Cas9, foram questionados posteriormente por EGLI, Dieter et al. (2018). Entretanto, para efeitos de análise, o mais importante é a manipulação de embriões nos Estados Unidos do experimento supracitado.

5 Do inglês "double-strand breaks" do DNA.

Veredas do Direito, Belo Horizonte, ·v.16 · n.34 · p.123-152 $\cdot$ Janeiro/Abril de 2019 
p. 945). Mas, também, um maior controle em sua aplicação: “Controlling DNA damage signaling, such that efficient gene correction can occur but the formation and selection of potentially tumorigenic cells are suppressed, will be important in developing safer and more efficient next generation genome editing technologies." (HAAPANIEMI et al., 2018, p. 930).

A pesquisa conduzida por Kosicki, Tomber e Bradley (2018), por sua vez, percebeu que o uso do CRISPR-Cas9 causa efeitos destrutivos em locais diferentes onde ocorreu o corte do DNA, destruindo outros DNAs que não estavam envolvidos no processo, o que pode causar sérias consequências patogênicas, inclusive com o surgimento de genes causadores de cânceres:

In the clinical context of editing many billions of cells, the multitude of different mutations generated makes it likely that one or more edited cells in each protocol would be endowed with an important pathogenic lesion. Such lesions may constitute a first carcinogenic 'hit' in stem cells and progenitors, which have a long replicative lifespan and may become neoplastic with time (KOSICKI; TOMBERG; BRADLEY, 2018, p. 770).

Na visão dos autores, tem havido uma negligência nas pesquisas envolvendo o uso do CRISPR-Cas9 em certos casos, já que deveria ser ainda mais trabalhado:

We speculate that current assessments may have missed a substantial proportion of potential genotypes generated by on-target Cas 9 cutting and repair, some of which may have potential pathogenic consequences following somatic editing of large populations of mitotically active cells (KOSICKI; TOMBERG; BRADLEY, 2018, p. 765).

No final de 2018, um experimento usando a técnica CRISPR-Cas9 faria um tumulto no meio científico: um pesquisado chinês, He Jiankui, de Shenzhen, anunciou que implantou embriões manipulados com a técnica CRISPR-Cas9, o que resultou no nascimento de duas meninas gêmeas, que seriam, portanto, os primeiros humanos nascidos editados geneticamente. Sua pesquisa consistiu em desabilitar um gene, denominado CCR5, que permite o acesso do vírus da Aids (HIV) em uma célula. Sua justificativa foi a de tornar os organismos resistentes à doença, muito comum na China e de que os filhos concebidos não tivessem a doença dos progenitores (ele usou pais com HIV e mães sem o vírus). O método consistiu em: 
The gene editing occurred during IVF, or lab dish fertilization. First, sperm was "washed" to separate it from semen, the fluid where HIV can lurk. A single sperm was placed into a single egg to create an embryo. Then the gene editing tool was added.

When the embryos were 3 to 5 days old, a few cells were removed and checked for editing. Couples could choose whether to use edited or unedited embryos for pregnancy attempts. In all, 16 of 22 embryos were edited, and 11 embryos were used in six implant attempts before the twin pregnancy was achieved, He said.

Tests suggest that one twin had both copies of the intended gene altered and the other twin had just one altered, with no evidence of harm to other genes, He said. People with one copy of the gene can still get HIV, although some very limited research suggests their health might decline more slowly once they do (MARCHIONE, 2018).

Houve sérias dúvidas da comunidade científica de que a pesquisa tenha ocorrido, já que ela não saiu em qualquer revista científica que pudesse ser analisada por outros pesquisadores. Ocorreram também questionamentos sobre a forma como He Jiankui recrutou os participantes da pesquisa, já que talvez não tivesse sido claro quanto ao método empregado. Alguns cientistas questionaram o fato de que a edição do gene CCR5 poderia também possibilitar o surgimento de outras doenças. Não estava claro também se o pesquisador procedeu de maneira correta perante os órgãos competentes e as instituições envolvidas. Há ainda o questionamento de que existem pessoas cujo organismo sofre uma mutação natural no gene CCR5, que os torna imunes ao HIV e que, por isso, o teste feito teria como justificativa implícita a pura e simples aplicação da técnica (MARCHIONE, 2018). E a questão mais fundamental: Teria He Jiankui cruzado uma linha arriscada, ou teria ele sido o pioneiro de algo inevitável?

O suposto experimento gerou uma reação em cadeia. Vários cientistas criticaram o fato dele ter sido feito sem ainda haver um consenso no meio científico sobre a edição genética em seres humanos e sua implantação. Na própria China, país de origem do autor da pesquisa, onde há autorização para a edição genética, um grupo de 122 cientistas escreveu uma carta aberta em que chamam He Jiankui de louco e afirmam que tal atividade foi um duro golpe na reputação e no desenvolvimento científico da China (KOLATA; WEE; BELLUCK, 2018). Alguns dias depois, o governo chinês proibiu He Jiankui de realizar mais pesquisas, posteriormente, foi detido em uma hospedagem da Universidade de Ciência e Tecnologia do Sul da China, em Shenzhen, sendo, por fim, demitido da 
mesma Universidade, onde trabalhava. As autoridades chinesas, que após uma investigação confirmaram os feitos do pesquisador, provavelmente tomarão medidas duras contra ele e sua equipe, enquadrando-os em acusações criminais (RAMZY; WEE, 2019).

\section{A BIOSSEGURANÇA E A LEI BRASILEIRA N. 11.105/2005}

Os incipientes experimentos envolvendo a técnica CRISPRCas9 levantam problemas de segurança e ética nos procedimentos de manipulação genética.

Certo é que há riscos ainda desconhecidos e a Biossegurança deve atuar na prevenção desses riscos internos (laboratoriais) e externos (na liberação dos organismos modificados).

A Biossegurança é o conjunto de técnicas e procedimentos que atua junto às pesquisas com material biológico, buscando a prevenção, a eliminação ou a diminuição dos riscos à saúde humana e ao meio ambiente, bem como a manutenção do equilíbrio dos ecossistemas.

$\mathrm{Na}$ atuação junto à biotecnologia, pode-se afirmar que a Biossegurança é mais pragmática que a Bioética, porque objetiva implementar procedimentos de segurança, que devem abranger atividades de investigação, ensino, produção e distribuição de inventos e de produtos biotecnológicos, bem como o desenvolvimento e a prestação de serviços relacionados à biotecnologia.

Schramm (2010) afirma que a Bioética pode ser considerada um novo âmbito da Filosofia Moral. Sua tarefa seria observar e discutir os avanços biotecnocientíficos. Já a Biossegurança seria um novo campo da biotecnociência, preocupada com a segurança dos procedimentos científicos. "Em suma, a bioética analisa a moralidade das biotecnologias e a biossegurança calcula e pondera os riscos inerentes às biotecnologias do ponto de vista de sua segurança." (SCHRAMM, 2010, p. 105).

O marco inicial da biossegurança contemporânea está nas reuniões de Asilomar, na Califórnia, onde em 1975 ocorreu uma série de reuniões, envolvendo importantes cientistas que discutiam sobre a ética na pesquisa. O assunto mais relevante, naquele momento, foi a sugestão de moratória de pesquisas genéticas, ocorrida no ano anterior por uma parcela de cientistas.

Por meio dessa reunião foram estabelecidas diretrizes para a segurança dos experimentos com DNA recombinante. Apesar da expressão "biossegurança" não ter sido utilizada na época, foi o documento de 
Asilomar que lançou as bases da biossegurança.

Hoje, os procedimentos de biossegurança ocupam-se principalmente de:

- Identificar os riscos de atividades que envolvam manuseio de material biológico;

- Caracterizar os riscos segundo a probabilidade de seus efeitos e o alcance de suas possíveis consequências;

- Analisar níveis de exposição aceitáveis a materiais perigosos ou com riscos ainda desconhecidos;

- Avaliar a probabilidade dos efeitos negativos da atividade;

- E, em caso de danos, avaliá-los e propor medidas de contenção e reparação.

No Brasil, o principal instrumento regulador da Biossegurança é a Lei n. 11.105 - Lei de Biossegurança - sancionada pelo Presidente da República em 24 de março de 2005.

Como aspectos gerais, a Lei de Biossegurança estabelece normas de segurança e mecanismos de fiscalização sobre construção, cultivo, produção, manipulação, transporte, transferência, importação, exportação, armazenamento, pesquisa, comercialização, consumo, liberação no meio ambiente e descarte de organismos geneticamente modificados, tendo como diretrizes o estímulo ao avanço científico na área de biossegurança e biotecnologia, a proteção à vida e à saúde humana, animal e vegetal, e a observância do princípio da precaução para a proteção do meio ambiente (BRASIL, 2005, art. $1^{\circ}$ ).

A Lei de Biossegurança trata, como temas centrais, da pesquisa com células-tronco embrionárias e da pesquisa e liberação de organismos geneticamente modificados. No entanto, ela também cria restrições a manipulações genéticas.

A tramitação da Lei foi tumultuada, com pressão de grupos econômicos interessados na modificação genética de soja, até então desregulamentada. Foi durante a tramitação que o Presidente da República assinou a Medida Provisória n. 223, de 14 de outubro de 2004 - mais tarde convertida na Lei n. 11.092, de 12 de janeiro de 2005 -, liberando o plantio da soja transgênica da safra 2004-2005 e a comercialização do produto até 31 de janeiro de 2006.

Após a promulgação da Lei, outra celeuma se instaurou com relação à pesquisa com células-troncos embrionárias. Em 30 de maio 
de 2005, o então Procurador-Geral da República, Cláudio Fonteles, protocolizou petição questionando a constitucionalidade do artigo $5^{\circ}$ da Lei de Biossegurança, que permite a utilização de embriões humanos excedentes das técnicas de fertilização in vitro em pesquisas e terapias.

O Procurador-Geral da República mostrou-se indignado com o tratamento normativo dado ao embrião humano crioconservado, excedente de fertilização in vitro. A utilização desse, em pesquisas e terapias, implicava, necessariamente - pelo menos ao tempo de promulgação da Lei e propositura da Ação Direta de Inconstitucionalidade - na destruição do embrião.

Sob o argumento de que " $a$ vida humana acontece na, e a partir $d a$, fecundação", o artigo $5^{\circ}$ da Lei de Biossegurança ofenderia o artigo $1^{\circ}$, III, e o caput do artigo $5^{\circ}$ da Constituição Federal. O membro da ProcuradoriaGeral da República considerou, pois, embriões humanos como seres constitucionalmente idênticos ao ser humano nascido, buscando, para tanto, auxílio em opiniões de médicos, geneticistas e biólogos.

O julgamento da ADI n. 3.510-0 iniciou-se em março de 2008, ocasião em que se manifestaram pela constitucionalidade do artigo $5^{\circ}$ o Ministro Relator Dr. Carlos Ayres de Britto e a então Presidente do Supremo Tribunal Federal, Ministra Ellen Gracie. A seção foi suspensa em razão de pedido de vista do Ministro Carlos Alberto Menezes Direito. Retomado o julgamento em 28 de maio de 2008, os Ministros Menezes Direito e Ricardo Lewandowski votaram pela parcial procedência do pedido de inconstitucionalidade do artigo $5^{\circ}$ da Lei de Biossegurança. A Ministra Cármen Lúcia Rocha e o Ministro Joaquim Barbosa julgaram-no improcedente. Pela improcedência manifestaram, também, os Ministros Eros Grau e Cezar Peluso, porém, com determinadas ressalvas, nos termos dos seus votos. O julgamento foi suspenso e retomado no dia seguinte, 29 de maio de 2008. Colhidos os votos dos demais Ministros (Min. Celso Mello, Min. Marco Aurélio e Min. Gilmar Mendes) (BRASIL, 2008).

Enfim, o Supremo Tribunal Federal, por maioria e nos termos do voto do Relator, julgou improcedente o pedido constante na Ação Direta de Inconstitucionalidade n. 3.510-0, vencidos parcialmente, em diferentes extensões, os Ministros Menezes Direito, Ricardo Lewandowski, Eros Grau, Cezar Peluso e Gilmar Mendes, sendo então permitida a pesquisa com células-tronco embrionárias, especialmente a partir da diferenciação do tratamento jurídico dado ao nascituro daquele despendido ao embrião não gestado e congelado como excedentário de técnicas de reprodução humana assistida (BRASIL, 2008).

As pesquisas e terapias com embriões humanos são permitidas 
pela Lei de Biossegurança apenas quanto às células-tronco, sendo proibida qualquer técnica de engenharia genética, donde se pode inferir que também está proibida a técnica CRISPR-Cas9. O art. 24 tipifica como crime, e pune com detenção, de 1 a 3 anos, e multa, a conduta de utilizar embrião humano em desacordo com as disposições do art. $5^{\circ}$, ou seja, a utilização dos embriões deve observar os seguintes requisitos: a) a pesquisa e a terapia devem ter por objeto células-tronco; b) devem os genitores consentir expressamente na utilização; c) aprovação prévia dos comitês de ética em pesquisa das instituições de pesquisa e serviços de saúde envolvidos; e d) não se destinar à comercialização de material biológico (BRASIL, 2005).

Já a alteração genética em embrião recebeu tipificação própria, sendo crime punível com reclusão, de 1 a 4 anos, e multa (BRASIL, 2005, art. 25).

Também é vedada a engenharia genética em célula germinal humana, o que foi incluído no tipo do art. 25, com as mesmas punições relativas ao embrião.

A proibição de engenharia genética em embriões e células germinativas humanas foi inserida com o objetivo de evitar uma possível eugenia, ou mesmo práticas abusivas e invasivas.

Por fim, a Lei de Biossegurança proíbe a clonagem humana, em qualquer de suas formas, seja reprodutiva ou terapêutica (BRASIL, 2005).

A clonagem é o processo de reprodução assexuada, produzida artificialmente, baseada em um único patrimônio genético, com ou sem utilização de técnicas de engenharia genética. Se for clonagem reprodutiva, o objetivo final será a obtenção de um novo indivíduo, geneticamente igual ao anterior. Se a clonagem for terapêutica, seu objetivo será a produção de células geneticamente idênticas que possam ser utilizadas em tratamento médico.

A clonagem está proibida por meio do artigo 26, que prevê punição de 2 a 5 anos de reclusão e multa para aquele que a realizar (BRASIL, 2005). 


\section{BIOÉTICA E TERAPIA GÊNICA}

Em relação à saúde humana, a técnica CRISPR-Cas9 abre margem para o aprimoramento e a ampliação da terapia gênica, que consiste no tratamento de doenças, herdadas ou adquiridas, em que se manipulam os genes defeituosos a fim de alcançar a cura ou estagnação da anomalia.

Em teoria, a terapia gênica pode se realizar em células somáticas e células germinativas, embora nestas últimas o risco seja muito maior, pois a alteração dos gametas pode resultar alterações inesperadas, como malformações e doenças até então desconhecidas. Há, inclusive, o risco de gerar problemas recessivos que poderão se manifestar apenas em gerações futuras.

Antes da técnica CRISPR-Cas9, a terapia somática era realizada por um vetor, retrovírus ou adenovírus, que inseria o novo material genético nas células doentes. Os vírus atuam como vetores eficientes por possuírem uma programação genética que lhes leva a transferir seu material genético para o organismo infectado.

Alguns retrovírus e adenovírus possuem ampla capacidade de propagação de seu material genético sem destruição das células do organismo invadido. Na terapia somática, retira-se parte do genoma do vírus, mantendo sua capacidade de reprodução e transferência, e se insere o material genético saudável a ser transportado. Ao infectar as células do paciente, o vírus transfere o material genético que está portando para as células doentes do organismo, modificando sua estrutura (SÁ; NAVES, 2018).

Já a técnica do CRISPR-Cas9 não se utiliza de outro organismo, como o retrovírus ou o adenenovírus. O CRISPR é uma sequência de DNA que pode ser repetida diversas vezes, com sequências únicas entre as repetições, e que permite cortar o DNA em lugares específicos. O Cas9 é a enzima responsável por esse corte. Então, por meio de uma cadeia-guia de RNA, retira-se um pedaço do DNA cortado e o substitui por outro.

Aparentemente mais eficaz, a técnica do CRISPR-Cas9 seria mais precisa que a terapia por intermédio do vírus.

Watson e Berry (2005) contam que a primeira bem-sucedida terapia gênica ocorreu em 1990, nos National Institutes of Health. As pacientes foram duas crianças que sofriam da deficiência de adenosina deaminase (ADA), Ashanti DeSilva, de quatro anos, e Cindy Cutshall, de nove anos. 
A ADA, que ocorre pela ausência de uma enzima, "desativa" o sistema imunológico, deixando o paciente vulnerável a qualquer doença.

Células do sistema imunológico das duas meninas foram colhidas e cultivadas em laboratório, e depois infectadas por retrovírus contendo o material genético desejado. O DNA do retrovírus foi transferido às células, que foram reinseridas nas pacientes. Várias infusões foram feitas durante alguns meses. Paralelamente à terapia gênica, as meninas foram submetidas à substituição enzimática, por exigência do National Institutes of Health.

Watson e Berry relatam os resultados:

\begin{abstract}
Posso atestar pessoalmente que Cutshall parecia uma menina muito saudável de onze anos quando ela e sua família visitaram Cold Spring Harbor, em 1992. Onze anos depois, porém, os resultados não se mostraram tão conclusivos. $\mathrm{O}$ funcionamento do sistema imunológico de DeSilva está próximo do normal, mas somente cerca de um quarto de suas células $\mathrm{T}$ proveio da terapia gênica. $\mathrm{O}$ sangue de Cutshall tem uma proporção ainda menor de células $\mathrm{T}$ provenientes da terapia, embora seu sistema imunológico também esteja funcionando bem. Contudo, é difícil dizer exatamente quanto dessa melhora se deve à terapia gênica e quanto é uma decorrência do tratamento enzimático contínuo. O resultado, pois, é ambíguo demais para ser interpretado como um sucesso inequívoco da terapia gênica (WATSON; BERRY, 2005, p. 377-378).
\end{abstract}

Alguns problemas podem ser apontados nesse tipo de terapia, como demonstra o próprio caso de DeSilva e Cutshall. As células submetidas ao tratamento possuem pequeno tempo de vida, o que significa que o material genético sadio geralmente não consegue atingir a totalidade das células doentes. Também é clara a dificuldade em se atingir somente aquelas que necessitam do gene substituto. No caso de DeSilva e Cutshall, as células a serem tratadas podiam ser obtidas facilmente, por se tratarem de células do sistema imunológico.

Por fim, a terapia gênica somática apresenta incalculável potencial oncogênico. Pode-se perceber esse risco a partir de um caso ocorrido na França, em 2000. No Hospital Necker, de Paris, sob a chefia de Alain Fischer, dois bebês com ADA foram submetidos à terapia. A inovação ficou por conta da utilização de células-tronco da medula óssea dos bebês. Assim, quando as células-tronco se reproduzissem, gerariam automaticamente células com genes saudáveis, numa "correção genética autorregenerante." (WATSON; BERRY, 2005, p. 380).

Os resultados da terapia foram incríveis nos primeiros anos, mas 
em 2002, descobriu-se que um dos bebês apresentava quadro de leucemia. Embora o risco oncogênico seja real, no caso da ADA o resultado obtido ainda pode ser considerado vantajoso, em razão de suas características e dificuldades com tratamentos.

Esses riscos apresentados pela terapia gênica por meio de vírus, como o menor tempo de vida celular e o aumento do potencial oncogênico, podem também se manifestar na técnica CRISPR-Cas9, como relatado acima.

Além desses riscos, Habermas (2016) coloca importantes questões éticas a serem consideradas na produção de seres humanos programados geneticamente. Há, com essas técnicas, uma alteração da "autocompreensão ética da espécie" que rompe com a noção existencial do que somos e nos conduz a uma possibilidade de disposição orgânica construída. De algo dado, passa-se ao que nos damos como organismo.

Além disso, há uma grande preocupação do filósofo alemão com a autocompreensão da própria pessoa editada geneticamente: "Não podemos excluir o fato de que o conhecimento de uma programação eugênica do próprio patrimônio hereditário limita a configuração autônoma da vida do indivíduo e mina as relações fundamentalmente simétricas entre pessoas livres e iguais." (HABERMAS, 2016, p. 33)

A permissão para interferir no genoma em busca de contribuição para a saúde da pessoa pode ser vista como benéfica, mas é muito tênue o limite que norteia o que é bom, preferível ou ruim. O que é realmente terapêutico e o que é apenas desejável?

\footnotetext{
Uma intervenção genética não abre o espaço de comunicação para dirigir-se à criança planejada como uma segunda pessoa e incluí-la num processo de compreensão. [...] As intervenções eugênicas de aperfeiçoamento prejudicam a liberdade ética na medida em que submetem a pessoa em questão a intenções fixadas por terceiros, que ela rejeita, mas que são irreversíveis, impedindo-a de se compreender livremente como o autor único de sua própria vida. Pode ser que seja mais fácil identificar-se com capacidades e aptidões do que com disposições ou até qualidades; porém, para a ressonância psíquica da pessoa em questão, importa apenas a intenção que estava ligada ao propósito da programação. Somente no caso de se evitar males extremos e altamente generalizados, é que surgem bons motivos para se aceitar o fato de que o indivíduo afetado concordaria com o objetivo eugênico (HABERMAS, 2016, p. 86-88).
} 
A posição de Habermas na obra O futuro da natureza humana foi uma resposta a um escrito do também filósofo alemão Peter Sloterdijk ${ }^{6}$, que se tornaria a obra Regras para o parque humano: uma resposta à carta de Heidegger sobre o Humanismo. Sem voltar propriamente à querela entre os dois pensadores, é importante destacar o posicionamento de Sloterdijk frente ao avanço tecnocientífico.

Para Sloterdijk, o ocidente foi marcado pelo humanismo, uma determinada formação que teria a capacidade de conter os instintos destrutivos humanos: "The latent message of humanism, then, is the taming of men. And its hidden thesis is: reading the right books calms the inner beast" (SLOTERDIJK, 2009, p. 15). Nesse sentido, há uma crença no humanismo de que os humanos são influenciáveis e de que é fundamental oferecer um certo tipo de controle. As tendências bestializadoras e tendências domesticadoras estariam em constante embate no ser humano: "The label of humanism reminds us (with apparent innocuousness) of the constant battle for humanity that reveals itself as a contest between bestializing and taming tendencies." (SLOTERDIJK, 2009, p. 15).

Ao interpretar a Carta Sobre o Humanismo, de Heidegger, escrita após a II Grande Guerra, em 1946, Sloterdijk, partindo da crítica daquele de que o humanismo (e suas derivações, o cristianismo, o marxismo e o existencialismo) está inserido na tradição metafísica do esquecimento do ser, percebe o seguinte questionamento formulado por Heidegger, que coloca em questão o humanismo: "Why should humanism and its general philosophical self-representation be seen as the solution for humanity, when the catastrophe of the present clearly shows that it is man himself, along with his systems of metaphysical self-improvement and self-clarification, that is the problem?" (SLOTERDIJK, 2009, p. 17). Após duas grandes guerras, feitas por uma Europa educada e humanista, nada mais natural do que questionar a formação que fora pautada no humanismo e sua concepção milenar de que o ser humano é um animal rationale. O que interessa a Sloterdijk de sua leitura de Heidegger é o fato do humanismo, enquanto domesticação humana, ter sido criticado. O que colocar, então, no lugar?

$6 \mathrm{O}$ debate Habermas-Sloterdijk teve origem quando alguns jornalistas publicaram trechos descontextualizados de uma palestra de Sloterdijk (originalmente apresentada em 15 de junho de 1997 na cidade da Basileia, num evento sobre o humanismo e depois retomada em junho de 1999 num colóquio sobre Heidegger e Levinas em Elmau e que dará origem ao texto Regras para o parque humano), dando a entender que o autor era a favor de práticas eugênicas. A reação de Habermas, que ocorrerá, inicialmente, na imprensa de maneira violenta, resultará na obra $\mathrm{O}$ futuro da natureza humana. Em nossa visão, Habermas jamais compreendeu efetivamente o texto de Sloterdijk. 
What can tame man, when the role of humanism as the school for humanity has collapsed? What can tame men, when their previous attempts at self-taming have led primarily to power struggles? What can tame men, when after all previous experiments to grow the species up, it remains unclear what it is to be a grown-up? Or is it simply no longer possible to pose the question of the constraint and formation of mankind by theories of civilizing and upbringing? (SLOTERDIJK, 2009, p. 20).

Dando sequência em sua análise, Sloterdijk(2009) retoma Nietzsche para deduzir, a partir desse, que o ser humano é compreendido como tendo uma força domesticadora e uma força criadora. A sociabilização acabou produzindo homens que são domesticados, mas, através de sua força criadora, o homem criará o super-homem. E é dessa força criadora que Sloterdijk, apesar de fazer ressalvas ao pensamento de Nietzsche, capta a fundamental questão de nossa época: a capacidade, através da técnica, de, literalmente, criar "novos seres humanos".

But the discourse about difference and the control of taming and breeding - indeed, just the suggestion about the decline of awareness of how human beings are produced, and indeed of anthropotechnology - these are prospects from which we may not, in the present day, avert our eyes, lest they once again be presented as harmless (SLOTERDIJK, 2009, p. 23).

Sloterdijk, andando em terreno perigoso, o que gera uma querela iniciada, talvez, por uma leitura apressada de Habermas, afirma que a história da cultura é uma história de seleção, desde letrados e iletrados, e que há dois tipos de humanos, os que criam e os que são criados, sendo que a era da técnica perpetua tal divisão, caminhando para uma problematização em nível biológico. A humanidade terá que debater, como a técnica CRISPR-Cas9 demonstrou, os avanços técnicos e sua capacidade de manipulação da natureza em geral e da humana. Onde o humanismo falhou para conter os impulsos destrutivos, ter-se-á a técnica. E como afirma Sloterdijk, a humanidade não poderá fugir às questões sobre sua própria autodeterminação:

But whether this process will also eventuate in a genetic reform of the characteristics of the species; whether the present anthropotechnology portends an explicit future determination of traits; whether human beings as a species can transform birthfatalities into optimal births and prenatal selection - these are questions with which, 
Por fim, Sloterdijk (2009) se volta para Platão e sua obra O político, na qual ele encontra a noção, já nos primórdios da cultura ocidental, de que a arte da política é a arte de pastorear a cidade. Por isso, todo o pensamento ocidental se debruçou na insidiosa tarefa de pensar a comunidade humana como um parque zoológico, já que o ser humano é também um animal que quer, voluntariamente, ser cuidado por outros, os peritos, aqueles que sabem como unir as melhores qualidades humanas, ideia essa que está mais do que escancarada nesta era biotecnológica e que, inevitavelmente, terá a técnica CRISPR-Cas9 como um dos expoentes.

Assim, o espaço da Bioética nessa discussão deve ser ampliado para que permita entender que qualquer decisão a respeito da técnica CRISPRCas9 implicará em uma série de responsabilidades com as gerações presentes e futuras, sendo forçoso não escapar de suas interferências na natureza e consequências.

Invoca-se a Bioética Global como importante agente de reflexão em tema tão espinhoso, posto que Genética exige uma Bioética que se projeta "into the future leads even to a 'subject' who does not exist, does not claim and does not have his rights harmed: future generations. Moreover, it also addresses other forms of life, since ethics becomes a part of the philosophy of nature." (REIS; NAVES; RIBEIRO, 2018, p. 84).

\section{CONCLUSÃO}

Não se pode afirmar com absoluta certeza que a técnica CRISPR-Cas9 irá se consolidar no meio científico. A ciência séria é feita paulatinamente por meio de provas, contraprovas, experimentos e discussões. Há, portanto, um longo caminho a percorrer. Entretanto, não se pode negar que o potencial da técnica é inegável.

O CRISPR-Cas9 tem a capacidade de adentrar inúmeras áreas práticas que vão desde a produção de alimentos, passando pela manipulação de populações animais, pela área de fármacos e, enfim, pela biotecnologia, com destaque para a manipulação em células germinativas e embriões. Os interesses econômicos, sociais, políticos e científicos fazem com que o assunto frequentemente seja abordado de maneira exaltada.

Depois de apresentar a técnica CRISPR-Cas9, do seu surgimento 
até o uso em embriões implantados, o artigo apresentou elementos da Lei de Biossegurança no Brasil. Ainda, valendo-se do debate entre os pensadores alemães Habermas e Sloterdijk, o texto expôs as preocupações com o uso do CRISPR-Cas9 na prática eugênica, mas também levanta a hipótese de um inevitável uso da técnica nos seres humanos.

Como a técnica, normalmente, está sempre à frente de uma reflexão ética-filosófica e de um posicionamento jurídico, é extremamente necessário que ambas as áreas (Filosofia e Direito) reflitam com cuidado os potenciais explosivos da técnica CRISPR-Cas9. A virtual mudança em todos os aspectos da realidade torna a técnica CRISPR-Cas9 objeto claro de estudo para a Filosofia (Ambiental), o Direito (Ambiental) e a Bioética (Ambiental).

\section{REFERÊNCIAS}

BARRANGOU, Rodolphe et al. CRISPR provides acquired resistance against viruses in prokaryotes. Science, v. 315, p. 1709-1712, mar. 2007. Disponível em: <https://www.ncbi.nlm.nih.gov/pubmed/17379808>. Acesso em: 10 jan. 2019.

BRASIL. Lei $n$. 11.105, de 24 de março de 2005. Regulamenta os incisos II, IV e V do $\S 1^{\circ}$ do art. 225 da Constituição Federal, estabelece normas de segurança e mecanismos de fiscalização de atividades que envolvam organismos geneticamente modificados - OGM e seus derivados, cria o Conselho Nacional de Biossegurança - CNBS, reestrutura a Comissão Técnica Nacional de Biossegurança - CTNBio, dispõe sobre a Política Nacional de Biossegurança - PNB, revoga a Lei n. 8.974, de 5 de janeiro de 1995, e a Medida Provisória n. 2.191-9, de 23 de agosto de 2001, e os arts. $5^{\circ}, 6^{\circ}, 7^{\circ}, 8^{\circ}, 9^{\circ}, 10$ e 16 da Lei n. 10.814 , de 15 de dezembro de 2003, e dá outras providências. Disponível em: $<$ http://www.planalto.gov. br/ccivil_03/_Ato2004-2006/2005/Lei/L11105.htm>. Acesso em: 5 fev. 2019.

BRASIL. Supremo Tribunal Federal. Ação Direta de Inconstitucionalidade n. 3.510-0. Constitucional. Ação direta de inconstitucionalidade. Lei de Biossegurança. Impugnação em bloco do art. $5^{\circ}$ da Lei $n^{\circ}$ 11.105, de 24 de março de 2005 (Lei de Biossegurança). Pesquisas com células-tronco embrionárias. Inexistência de violação do direito à vida. Constitucionalidade do uso de células-tronco embrionárias em pesquisas 
científicas para fins terapêuticos. Descaracterização do aborto. Normas constitucionais conformadoras do direito fundamental a uma vida digna, que passa pelo direito à saúde e ao planejamento familiar. Descabimento de utilização da técnica de interpretação conforme para aditar à Lei de Biossegurança controles desnecessários que implicam restrições às pesquisas e terapias por ela visadas. Improcedência total da ação. Relator: Ministro Carlos Ayres de Britto. Brasília, mar.-maio 2008. Disponível em: $\quad<$ http://www.stf.jus.br/portal/geral/montarMenuPdfPaginado. asp $?$ id $=611723 \&$ tipo $=$ AC\&descricao $=$ Inteiro $\% 20$ Teor $\% 20$ ADI $\% 20 / \% 20$ 3510>. Acesso em: 5 fev. 2019.

BROUNS, Stan J. J. et al. Small CRISPR RNAs Guide Antiviral Defense in Prokaryotes. Science, v. 321, p. 960-964, 2008. Disponível em: <http:// science.sciencemag.org/content/321/5891/960.long >. Acesso em: 10 jan. 2019.

CYRANOSKI, David. CRISPR gene editing tested in a person. Nature, v. 539, p. 479, nov. 2016. Disponível em: <https://www.nature.com/ polopoly_fs/1.20988!/menu/main/topColumns/topLeftColumn/pdf/ nature.2016.20988.pdf $>$. Acesso em: 18 jan. 2019.

DOUDNA, Jennifer; STERNBERG, Samuel. A crack in creation: the power to control evolution. London: Vintage, 2017.

EGLI, Dieter et al. Inter-homologue repair in fertilized human eggs? Nature, v. 560, p. E5-E7, ago. 2018. Disponível em: <https://www.nature. com/articles/s41586-018-0379-5.pdf> . Acesso em: 18 jan. 2019.

HAAPANIEMI, Emma et al. CRISPR-Cas9 genome editing induces a p53-mediated DNA damage response. Nature Medicine, v. 24, p. 927-930, jul. 2018. Disponível em: <https://www.nature.com/articles/s41591-0180049-z>. Acesso em: 18 jan. 2019.

HABERMAS, Jürgen. O futuro da natureza humana. Tradução de Karina Jannini. $2^{a}$ ed. São Paulo: WMF Martins Fontes, 2016.

IHRY, Robert J. et al. p53 inhibits CRISPR-Cas9 engineering in human pluripotent stem cells. Nature Medicine, v. 24, p. 939-946, jul. 2018. Disponível em: <https://www.nature.com/articles/s41591-018-0050-6>. Acesso em: 18 jan. 2019.

ISHINO, Yoshizumi et al. Nucleotide sequence of the iap gene, responsible 
for alkaline phosphatase isozyme conversion in Escherichia coli, and identification of the gene product. Jornal of Bacteriology, v. 169, p. 54295433, 1987. Disponível em: <https://www.ncbi.nlm.nih.gov/pmc/articles/ PMC213968/>. Acesso em: 10 jan. 2019.

JINEK, Martin et al. A Programmable Dual-RNA-Guided DNA Endonuclease in Adaptive Bacterial Immunity. Science, v. 337, p. 816-821, ago. 2012. Disponível em: <http://science.sciencemag.org/ content/337/6096/816/tab-pdf $>$. Acesso em: 10 jan. 2019.

KOLATA, Gina; WEE, Sui-Lee; BELLUCK, Pam. Chinese Scientist Claims to Use Crispr to Make First Genetically Edited Babies. New York Times, 26 nov. 2018. Disponível em: <https:/www.nytimes.com/2018/11/26/ health/gene-editing-babies-china.html $>$. Acesso em: 20 jan. 2019.

KOSICKI, Michael; TOMBERG, Kärt; BRADLEY, Allan. Repair of double-strand breaks induced by CRISPR-Cas9 leads to large deletions and complex rearrangements. Nature Biotechnology, v. 36, n 8, p. 765-771, Aug. 2018. Disponível em: <https://www.nature.com/articles/nbt.4192>. Acesso em: 18 jan. 2019.

LAMPHIER, Edward et al. Don't edit the human germ line. Nature, v. 519, p. 410-411, mar. 2015. Disponível em: <https://www.nature.com/polopoly_ fs/1.17111!/menu/main/topColumns/topLeftColumn/pdf/519410a.pdf $>$. Acesso em: 10 jan. 2019.

LEDFORD, Heid. CRISPR fixes embryo error. Nature, v. 548, p. 13-14, ago. 2017. Disponível em: <https://www.nature.com/polopoly_fs/1.22382!/ $\mathrm{menu} / \mathrm{main} /$ topColumns/topLeftColumn/pdf/nature.2017.22382a.pdf $>$. Acesso em: 18 jan. 2019.

MA, Hong et al. Correction of a pathogenic gene mutation in human embryos. Nature, v. 548, p. 413-419, ago. 2017. Disponível em: <https:// www.nature.com/articles/nature23305.pdf $>$. Acesso em: 18 jan. 2019.

MAKAROVA, Kira S. et al. A putative RNA-interference-based immune system in prokaryotes: computational analysis of the predicted enzymatic machinery, functional analogies with eukaryotic RNAi, and hypothetical mechanisms of action. Biology Direct, n. 1, 2006. Disponível em: $<$ https:// www.ncbi.nlm.nih.gov/pmc/articles/PMC1462988/pdf/1745-6150-1-7. pdf $>$. Acesso em: 10 jan. 2019. 
MARCHIONE, Marilynn. Chinese researcher claims first gene-edited babies. Associated Press. 26 Nov. 2018. Disponível em: <https://www. apnews.com/4997bb7aa36c45449b488e19ac83e86d $>$. Acesso em: 20 jan. 2019.

MOJICA, Francisco J. et al. Biological significance of a family of regularly spaced repeats in the genomes of Archaea, Bacteria and mitochondria. Molecular Microbiology, v. 36, n. 1, p. 244246, 2000. Disponível em: <https://onlinelibrary.wiley.com/doi/ pdf/10.1046/j.1365-2958.2000.01838.x>. Acesso em: 10 jan. 2019.

NATIONAL ACADEMIES OF SCIENCES, ENGINEERING, AND MEDICINE. Human Genome Editing: Science, Ethics, and Governance. Washington, DC: The National Academies Press, 2017. Disponível em: $<$ https://www.nap.edu/catalog/24623/human-genome-editing-scienceethics-and-governance>. Acesso em: $10 \mathrm{dez} .2018$.

PENNISI, Elizabeth. The CRISPR Craze. Science, v. 341, p. 833836, Aug. 2013. Disponível em: <http://science.sciencemag.org/ content/341/6148/833>. Acesso em: 10 jan. 2019.

RAMZY, Austin; WEE, Sui-Lee Scientist Who Edited Babies' Genes Is Likely to Face Charges in China. New York Times, 21 Jan. 2019. Disponível em: <https://www.nytimes.com/2019/01/21/world/asia/chinagene-editing-babies-he-jiankui.html>. Acesso em: 22 jan. 2019.

REIS, Émilien Vilas Boas; NAVES, Bruno Torquato de Oliveira; RIBEIRO, Luiz Gustavo Gonçalves. A legal-philosophical positioning against the metaphysics of the "isms": an analysis on animals. Veredas do Direito, Belo Horizonte, v. 15, n. 31, p.67-94, Jan.-Apr. 2018.

SÁ, Maria de Fátima Freire de; NAVES, Bruno Torquato de Oliveira. Bioética e biodireito. $4^{\mathrm{a}}$ ed. Belo Horizonte: Del Rey, 2018.

SCHRAMM, Fermin Roland. Bioética, biossegurança e a questão da interface no controle das práticas da biotecnociência: uma introdução. Revista Redbioética/UNESCO, ano 1, 1(2), p. 99-110, 2010.

SLOTERDIJK, Peter. Rules for the Human Zoo: A Response to the Letter on Humanism. Translated by Mary Varney Rorty. Environment and Planning D: Society and Space. Vol. 27, n. 1, p. 12-28, 2009. Disponível em: $<$ https://journals.sagepub.com/doi/10.1068/dst3 $>$. Acesso em: 10 jan. 2019 . 
VAN ERP, Paul B. G. et al. The history and market impact of CRISPR RNA-guided nucleases. Current Opinion in Virology, v. 12, p. 85-90, 2015. Disponível em: <https://www.sciencedirect.com/science/article/pii/ S1879625715000425?via\%3Dihub>. Acesso em: 10 jan. 2019.

WANG, $\mathrm{H}$. et al. One-Step Generation of Mice Carrying Mutations in Multiple Genes by CRISPR/Cas-Mediated Genome Engieering. Cell, v. 153, p. 910-918, 2013. Disponível em: <https://www.cell.com/action/ showPdf?pii=S0092-8674\%2813\%2900467-4>. Acesso em: 10 jan. 2019. WATSON, James D.; BERRY, Andrew. DNA: o segredo da vida. São Paulo: Companhia das Letras, 2005.

WIEDENHEFT, B. et al. Structural Basis for DNase Activity of a Conserved Protein Implicated in CRISPR-Mediated Genome Defense. Structure, v. 17, p. 904-912, 2009. Disponível em: <https://www.cell.com/ action/showPdf?pii=S0969-2126\%2809\%2900192-0>. Acesso em: 10 jan. 2019.

WIEDENHEFT, Blake; STERNBERG; Samuel H; DOUDNA, Jennifer A. RNA-guided genetic silencing systems in bacteria and archaea. Nature, v. 482, p. 331-338, Feb. de 2012. Disponível em: <https://www.nature.com/ articles/nature10886>. Acesso em: 10 jan. 2019.

Artigo recebido em: 18/02/2019. Artigo aceito em: 20/04/2019.

\section{Como citar este artigo (ABNT):}

REIS, E. V. B.; OLIVEIRA, B. T. CRISPR-CAS9, biossegurança e bioética: uma análise jusfilosófica-ambiental da engenharia genética. Veredas do Direito, Belo Horizonte, v. 16, n. 34, p. 123-152, jan./abr. 2019. Disponível em: <http://www.domhelder.edu.br/revista/index.php/veredas/article/ view/1490>. Acesso em: dia mês. ano. 